\title{
EFFECTS OF WATER DIESEL EMULSION ON DIESEL ENGINE
}

\author{
DATTA SAI K ${ }^{1}$, RADHA KRISHNA GOPIDESI ${ }^{2}$, PREMKARTIKKUMAR SR $^{3}$ \& NAGARJUNA $\mathbf{K}^{\mathbf{4}}$ \\ ${ }^{1,4}$ Department of Mechanical Engineering, Vignan's Lara Institute of Technology \& Science, \\ Vadlamudi, Guntur, Andhra Pradesh, India \\ ${ }^{2,3}$ Automotive Research Centre, School of Mechanical Engineering, VIT University, Vellore, India
}

\begin{abstract}
The Water Diesel Emulsion (WiDE) fuel shows nepotism in terms of environmental and economical aspects. In the present investigation, WiDE is used as fuel for the diesel engine. Here, WiDE was prepared with various water percentages in the range of 0 to 15 using the non ionic surfactant with a HLB value of 6.31. The WiDE was prepared by using ultrasonic probe Sonicator and the mean diameter of water droplet was measured by using the dynolite microscope. The investigation was run on a diesel engine with WiDE as fuel, for finding the effect of performance, emission, and combustion characteristics. The engine was operated at a compression ratio of 17.5 with variable loads from 0 to $100 \%$ with an increment of $25 \%$ load. From the obtained results, it shows that emulsion fuels show less $\mathrm{NO}_{X}$ emission when compared with the pure diesel. The amount of water concentration shows the greater effect on $\mathrm{NO}_{X}$ emissions. From the obtained results, WiDE 10 shows greater break thermal efficiency due to micro explosion phenomenon and the WiDE 15 shows higher cylinder pressure. But the emulsion fuel produced higher $\mathrm{HC}$ and $\mathrm{CO}_{2}$ emissions when compared with the diesel.

KEYWORDS: Combustion, Emulsion, Performance, Surfactants \& Emissions
\end{abstract}

Received: Dec 13, 2017; Accepted: Jan 03, 2018; Published: Jan 19, 2018; Paper Id.: IJMPERDFEB201873

\section{INTRODUCTION}

Diesel engines have high fuel to power generating capacity when compared with other engines [1]. It leads to continuous increasing of diesel engines for various applications, mostly in agricultural and engineering sectors [2]. However, diesel engines are more contributors for the environmental pollutants. Due to various reasons like higher combustion temperature, improper combustion of fuel, carbon and sulphur contents, etc. And also fossil fuel resources around the world have continuously diminishing due to an increase of utilization [3]. The above said factors ignite the interest towards work on alternative fuel for diesel from the past few decade research. Based on the literature survey, the WiDE fuel has more scope for replacing the diesel due to its unique properties [4]. Generally, emulsion is a combination of two different fluids that will not physically mix but one part will stay suspended with another [5]. In an emulsion there are two phases continuous phase and dispersed phase [6]. The surfactant is a blend of "surface active agent". Surfactants are used for reducing the surface tension of water by absorbing at the liquid-gas interface. It is also reduces the interfacial tension between oil and water by absorbing at the liquid-liquid interface. Most of the surfactants can also assemble in the bulk solution into aggregates that are known as "micelles". To stabilize the emulsions, 1, 2, and 3\% surfactants were used [7]. The emulsion are undergoes the micro-explosions and it forms the smaller fuel droplets. Due to droplets are explored into smaller particles. It was useful for the simply contact with the air for complete combustion. Emulsions are used for reducing 
the PM without declining the combustion efficiency.

Abu-Zaid [8] investigated the performance of diesel engine with WiDE as fuel. He concluded that 20\% WiDE has given $3.5 \%$ improvement in brake thermal efficiency when compared to pure diesel. When increasing the water percentage, it shows the simultaneous reduction in brake specific fuel consumption and the exhaust gas temperature. Armas [9] et al. carried out the investigation on emission characteristics of the diesel engine when it is fuelled with WiDE. They found that slight improvement of brake thermal efficiency and a significant reduction in emissions like $\mathrm{NO}_{\mathrm{X}}$, soot, Particulate Matter (PM), and unburned hydrocarbons. Baskar et al. [10] worked on diesel engine using WiDE with enriched oxygenated air as fuel. They reported enhancement in combustion characteristics and brake thermal efficiency.

\section{MATERIALS AND METHODS}

\section{Emulsion Preparation}

In the present research work, the ultrasonic probe Sonicator was used for emulsification process. It was a capacity of $1000 \mathrm{ml}$ solution preparation with frequency of $15000 \mathrm{~Hz}$. The ultrasonic probe Sonicator contains mainly three components; they are controller unit, chamber with an adjustable stand, and the ultra sonic probe. Generally, water and diesel are two immiscible liquids so water and diesel was mixed by using the non-ionic surfactants [11] of HLB value 6.31. The surfactants Span 80 with a HLB of 4.3 and Tween80 with a HLB of 15 were purchased from the online website Amazon. The quantity of surfactant used in this emulsion preparation was $1 \%$ by volume. The diesel purchased from Vellore HP petroleum station and the distilled water was used for the emulsion preparation. The water was added by the following percentages of 5, 10, and 15 by volume. The emulsion fuels are written as following WiDE 5 (5\% water), WiDE 10 (10\% water), WiDE 15 (15\% water). Initially the required amount of diesel was taken in glass beaker with volume of 1 litre and it mixes with above said surfactant. The beaker was placed in a plastic bowl and pours the ice cubes for controlling the temperature produced by ultrasonic probe Sonicator. Then the plastic bowl was placed inside the chamber of ultrasonic probe Sonicator on an adjustable stand. The probe was placed into the beaker and start machine. And then periodically add the small quantity of water to mixer of diesel and surfactants for proper mixing. The entire setup was clearly shown in the below Figure. 1. The process was continued till the proper mixing was observed visually, nearly it takes 90 to 100 minutes for $500 \mathrm{ml}$ of solution.

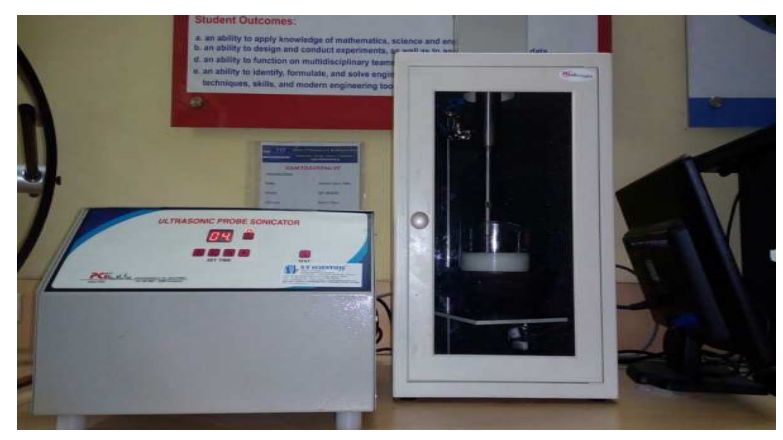

Figure 1: Ultrasonic Probe Sonicator

\section{Emulsion Stability}

The stability of water diesel emulsion plays a vital role in this investigation. The water diesel emulsion was kept in glass container and place in closed room with out in any disturbances of solution. The stability of water diesel emulsion was observed periodically and found that no deviation up to 30 days. So it indicates the stable nature of the emulsion. 


\section{Properties of Fuel}

The properties of diesel and water diesel emulsion were calculated by using various types of equipment. Here, the density was calculated by volume mass basis, the viscosities of fuels were measured by using Redwood viscometer 1 and the calorific value was determined by using bomb calorimeter. Flash and fire points were measured by using the Pensky Martens apparatus. Water diesel emulsion water droplet size was measured by Dino-Lite. The Dino-Lite was connected to the system with USB. First, install the Dino-Lite software file in the system and keep the icon on the desktop. The setup was shown in Figure. 2 and the images of the water droplet sizes are shown in the Figure. 3

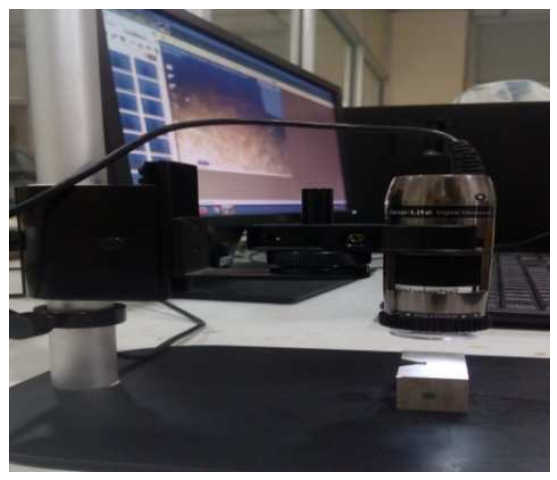

Figure 2: Dino-Lite with Computer Interface

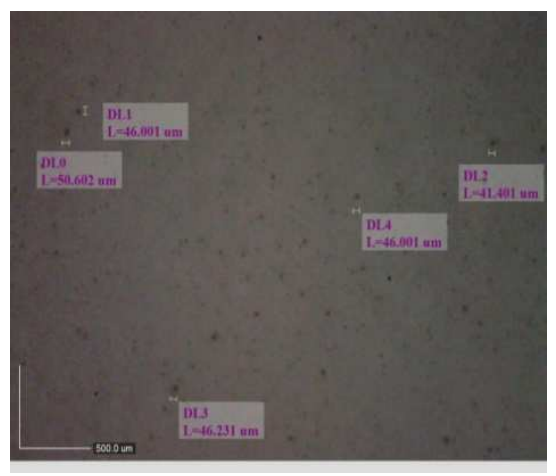

Figure 3: The Water Droplet Sizes Image

\section{Engine Setup}

For the present investigation used a four stroke single cylinder water cooled diesel engine setup. This setup contains computer interface for getting the automated data. It connected with AVL DI gas analyser for analyse the emissions like $\mathrm{CO}, \mathrm{CO} 2, \mathrm{NO}_{\mathrm{X}}, \mathrm{HC}$, and $\mathrm{O} 2$. Smoke was measured by using the AVL smoke meter. The engine setup connected with combustion encoder for combustion analysing. The engine setup was shown in Figure. 4.

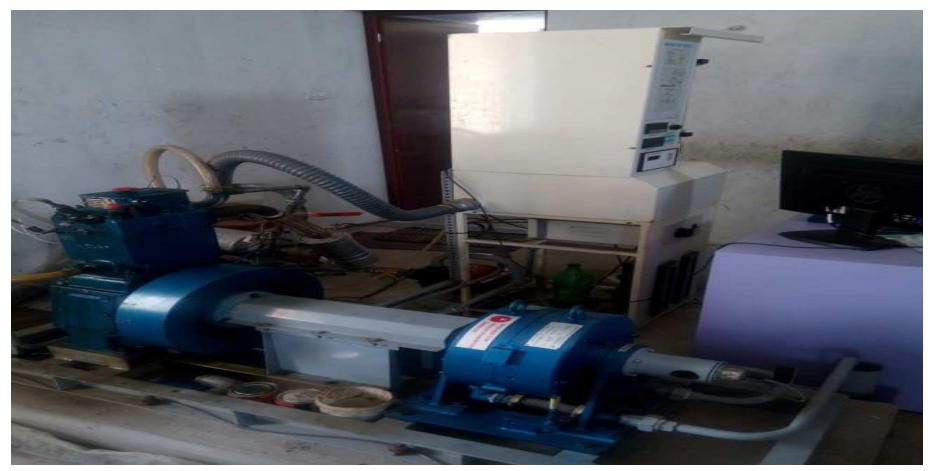

Figure 4: Four Stroke Single Cylinder Kirloskar Engine

\section{RESULTS \& DISCUSSIONS}

In this present investigation was carried out on diesel engine fuelled with various emulsion fuels with the water content of $5 \%, 10 \%$, and $15 \%$ were tested.

\section{Brake Thermal Efficiency}

The brake thermal efficiency is the ratio of brake power to the input power. From the obtained results observed that brake power and the brake thermal efficiency was increased with the increase in brake power in water-diesel emulsion. 
When compared to diesel fuel and the water-diesel emulsion, shows higher brake thermal efficiency. The Figure 5 shows relation between BP Vs Brake Thermal efficiency.

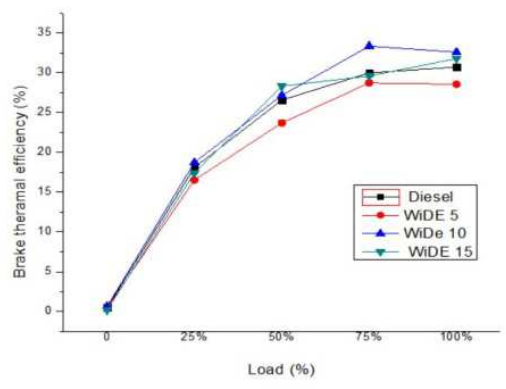

Figure 5: Brake Power Vs Brake Thermal Efficiency

From the above graph, it is observed that the maximum brake thermal efficiency for WiDE10 at full load condition due to the microexplosion phenomenon. But, initially WiDE decreases in brake thermal efficiency when compared to diesel due to lower combustion temperature. So based on the results obtained WiDE 10 was noted as the optimal blend.

\section{Combustion Analysis}

For the present investigation, used the data acquisition system for monitoring the combustion characters. The pressure transducers were fixed at the combustion chamber and at the fuel pump. Here, Figure 6 shows that the variation of crank angle and cylinder pressure for diesel and water-diesel emulsion. The Maximum cylinder pressure at full load condition was observed for diesel is 71.76 and water-diesel emulsions of 5\%,10\%,15\% are 72.11bar, 73.86bar, 79.93 bar respectively. Here, observed that $15 \%$ Wide shown higher cylinder pressure compared to others due to water needs high pressure for atomization.

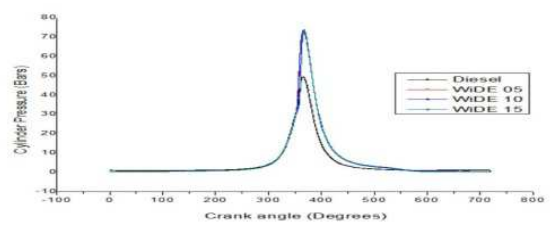

Figure 6: Crank Angle Vs Cylinder Pressure for Different Diesel and Wide

\section{Emissions Analysis}

\section{Nitrogen Oxide Emissions}

The nitrogen oxide formed due to higher combustion temperature. The formation of $\mathrm{NO}_{\mathrm{X}}$ from diesel and waterdiesel emulsion and W/D (E5, E10, and E15) was measured by using AVL Di gas analyser and it was found that a reduction in $\mathrm{NO}_{\mathrm{X}}$ in all types of W/D compared to Diesel. The water content in the emulsion showed the significant effect on $\mathrm{NO}_{\mathrm{X}}$ emissions formation. In the emulsion, WIDE10 is reported to be the best in reducing the $\mathrm{NO}_{\mathrm{X}}$ emissions with an average reduction of $51 \%$ load in every condition.

\section{Particulate Matter}

The formation of Particulate matter for diesel and water diesel emulsion (E5, E10, and E15) was noted from the result. It was clearly shown that the formation of PM in all types of water diesel emulsion was reduced when compared to 
diesel in all load conditions. The maximum reduction of PM is detected at high load. Where WiDE10 reduced the PM up to $70 \%$ in comparison to diesel, the average reduction of PM is about 55\% in every load condition. The reduction of PM when using W/D is due to the better mixing and atomization caused by the micro-explosion phenomena.

\section{CONCLUSION}

The present research work was mostly involved in the emulsion preparation methods and effects of emulsion on the diesel engine. From the above obtained results, the following conclusion is drawn

- The water-diesel gives better performance compared to diesel. The brake thermal efficiency for each blend was found to be high because of proper combustion.

- WiDE15 shown the higher mechanical efficiency when compared to diesel and other emulsions.

- $\quad$ The brake specific fuel consumption for WiDE 15 takes higher when compare to diesel. But the WiDE having low specific fuel consumption when compared to water-diesel.

- WiDE 10 Shows greater reduction of NOX emissions compared to the other fuels.

- The emulsion fuels produce higher $\mathrm{CO} 2$ and $\mathrm{HC}$ emissions compared to the diesel.

- $\quad$ The water diesel emulsions give the proper combustion fuel due to higher injection pressure when compared to diesel.

From the overall observation, WiDE 15 shows best alternative to diesel fuel.

\section{Scope of Future Work}

In the present research work, work was carried out on a single cylinder diesel engine without any modifications for evaluating the performance parameters.

In the future work, the experiment can be carried out by varying the operating parameters like injection pressure, compression ratio, and crank angle. And also more scope is available in the dual fuel mode with emulsion for increasing the performance parameters.

\section{REFERENCES}

1. B. K. Debnath, U. K. Saha, and N. Sahoo. A comprehensive review on the application of emulsions as an alternative fuel for diesel engines. Renew. Sustain. Energy Rev. 42; 2015: 196-211.

2. F. Y. H. Mohammed Yahaya Khan, Z. A abdul Karim. Review Article : current Trends in Water-in-diesels emulsion as a fuel. Sci. World J., 15; 2014.

3. Gopidesi Radha Krishna, Premkartik kumar SR. Applications of Emulsions as an Alternate Fuel for Bi-fuel engines- Review. Proc. Glob. Conf. Adv. Sci. Technol. Manag. 2017: 146-149.

4. A. K. Wamankar and S. Murugan. Combustion, performance and emission characteristics of a diesel engine with internal jet piston using carbon black- water- diesel emulsion. Energy, 91; 2015: 1030-1037.

5. K. A. Subramanian. A comparison of water - diesel emulsion and timed injection of water into the intake manifold of a diesel engine for simultaneous control of NO and smoke emissions. Energy Convers. Manag. 52(2); 2011: 849-857. 
6. L. Leng, X. Yuan, G. Zeng, H. Wang, H. Huang, and X. Chen. The comparison of oxidative thermokinetics between emulsion and microemulsion diesel fuel. Energy Convers. Manag. 101; 2015: 364-370.

7. S. A. Norazni et al. Stability behavior of non-surfactant water-in- diesel emulsion fuel using microscopic observation. MATEC Web Conf. 1059; 2017.

8. M. Abu-Zaid. Performance of single cylinder, direct injection Diesel engine using water fuel emulsions. Energy Convers. Manag. 45; 2004: 697-705.

9. O. Armas, R. Ballesteros, F. J. Martos, and J. R. Agudelo. Characterization of light duty Diesel engine pollutant emissions using water-emulsified fuel. Fuel 84 (7-8); 2005: 1011-1018.

10. P. Baskar and A. Senthilkumar. Effects of oxygen enriched combustion on pollution and performance characteristics of a diesel engine. Eng. Sci. Technol. an Int. J. 19(1); 2016: 438-443.

11. M. R. Noor El-Din, I. M. El-Gamal, S. H. El-Hamouly, H. M. Mohamed, M. R. Mishrif, and A. M. Ragab. Rheological behavior of water-in-diesel fuel nanoemulsions stabilized by mixed surfactants. Colloids Surfaces A Physicochem. Eng. Asp. 436;2013: 318-324.

12. Pradeep kumar A R, Annnamalai k, Premkartikkumar SR, Senthur NS. Effect of emulsified fuel on performance and emission characteristics in DI diesel engine. Journal of Chemical and Pharmaceutical Science.7; 2015: 215- 218 